\title{
HOW DID VERTEBRATES SHARPEN THEIR TEETH? A NEW PERSPECTIVE IN BIOAPATITE ANALYSIS
}

\author{
Martina Savioli ${ }^{1}$, Annalisa Ferretti ${ }^{1} \oplus$, Luca Medici $^{2} @ \&$ Daniele Malferrari ${ }^{1} @$ \\ ${ }^{1}$ Dipartimento di Scienze Chimiche e Geologiche, Università di Modena e Reggio Emilia, Via Campi 103, I-41125, Modena, Italy; martina. \\ savioli@unimore.it; annalisa.ferretti@unimore.it; daniele.malferrari@unimore.it \\ ${ }_{2}^{2}$ Istituto di Metodologie per l'Analisi Ambientale (IMAA-CNR), C. da S. Loja-Zona Industriale, I-85050, Tito Scalo, Potenza, Italy; luca. \\ medici@imaa.cnr.it
}

KEYWORDS:
bioapatite;
LA-ICP-MS;
Carcharias taurus tooth.

\section{Bullet-Points Abstract}

- A new approach for the analysis of bioapatite.

- LA-ICP-MS was used to characterized samples and standards.

- "In-house" matrix matched standard were prepared to optimize chemical analyses.

\section{INTRODUCTION}

Analytical methods in use in crystal-chemical characterization on crystalized (natural) material can be applied also in palaeontological investigation. X-ray microdifraction ( $\mu$-XRD) was tested for the first time on Ordovician conodonts from Normandy with anomalous overgrowth of apatite crystals on the surface of the elements (Ferretti et al., 2017). $\mu$-XRD allows not only to calculate bioapatite lattice cell parameters, but also to check for the presence of crystal preferred orientations through comparison of XRD detected signals changing sample orientation with respect to X-ray beam.

When we extended our investigation to other organisms sharing bioapatite use (e.g., shark and bony fish teeth, mammal and reptile bones, brachiopod shells, etc.), significant variations of cell parameter values came out. It is well known (Hughes \& Rakovan, 2002) that cell parameters are strictly dependent on chemical composition (i.e., isomorphic and iso- and hetero-valent substitutions that may occur in various coordination sites of bioapatite). Such information are usually achieved through microprobe measurements. Inductively coupled plasma mass spectrometry associated with a laser ablation device (LA-ICPMS) may be applied as well with the same purpose. Moreover, LA-ICPMS is also able to acquire at the same time (thus in the same sampling points) trace element measurements. However, a mass spectrometer like any measurement device requires an extremely accurate calibration procedure.

When laser ablation is employed, the interaction between laser and solid sample is complex and the response is dependent on the sample matrix. For this reason matrix-matched solid standards (frequently referred to as "external standards") are necessary to calibrate laser ablation processes to the instrument re- sponse. We thus tested several types of analytical standards, some of which certificated and on the market, and others in-house prepared starting from ultrapure reagents and certified analytical standards.

\section{Materials AND Methods}

NIST 610, NIST 612 and NIST 614 are the most commonly used analytical standard in LA-ICPMS. Here we prepared "In-house" matrix matched standard to analyze samples characterized by a bioapatite matrix (see next paragraph for further details). Measurements were carried out using a Thermo Fisher ICP-MS X Series II coupled with a New-Wave Laser Ablation system. The ablation products are sent to the inlet system of the spectrometer through an ultrapure He flow at $500 \mathrm{~mL} / \mathrm{min}$.

\section{Results AND Discussions}

Standards commonly used for LA-ICPMS analysis are NIST 610, NIST 612 and NIST 614. However, these standards share a glass matrix, material which is significantly harder than bones or teeth. As a result, when ablation conditions are applied, material removed from bioapatite samples is notably greater than that ablated from calibrating standards. Results will consequently be overestimated.

NIST Bone Ash and NIST Bone Meal represent a good alternative. However, as designed for measurements on water solution after mineralization, they are unable to provide concentration ranges (i.e., if used as a solid a single calibration point is detected). Bone Ash and Bone Meal can be diluted mixing them with a proper amount of an inert material (e.g., cellulose powder); however this procedure will drive to have standard under target concentration (i.e., a calibration 


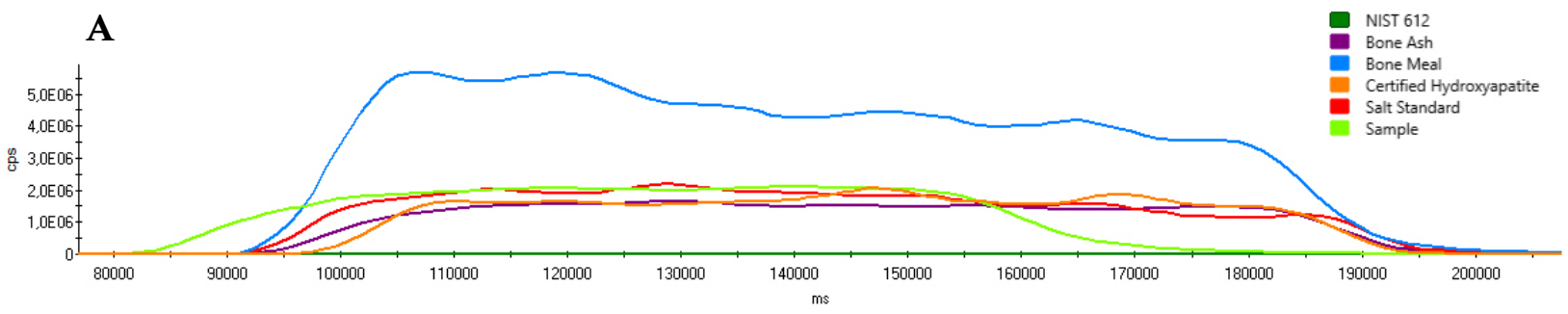

B

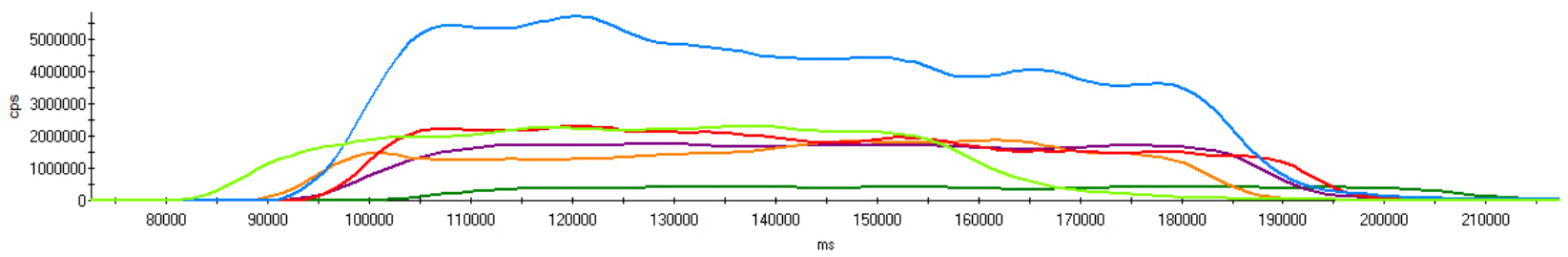

Fig. 1. The curves show a comparison between $\mathrm{P}(\mathbf{A})$ and $\mathrm{Ca}(\mathbf{B})$ from different standards, pure hydroxyapatite, and a Carcharias taurus tooth. Assuming that in Carcharias taurus tooth (Sample in the figure legend) the $\mathrm{P}$ and Ca content is that of a pure hydroxyapatite (about $40 \% \mathrm{Ca}, 18.5 \% \mathrm{P}$ ), we can observe that the signal from Bone Meal does not match those of the tooth, whereas signals from Bone Ash and in house made standards are both comparable to that of the tooth. cps, counts per second; ms, milliseconds.

curve that does not bracket samples concentrations). Moreover, Bone Ash and Bone Meal do not match our samples as far as the concentration of trace elements is concerned.

Here two in-house made and easy to prepare standards are proposed employing analytical reagents and/or certified analytical standards:

A mix between a micronized ultrapure synthetic hydroxyapatite with certified E-CRM 776-1 Firebrick standard that can supply elements like $\mathrm{Si}, \mathrm{Al}, \mathrm{Fe}, \mathrm{Mg}$, $\mathrm{K}$ and $\mathrm{Na}$ (all reported in fossilized bioapatites). The advantage provided by this method is that the chemical composition of the "ingredients" is known and certified and errors introduced during the preparation should be negligible. The disadvantage is that E-CRM 776-1 Firebrick is a silicate and, thus, the final matrix of the standard is not a pure hydroxyapatite.

A mix between a micronized ultrapure synthetic hydroxyapatite and ultrapure salts of the elements occurring in our samples. The advantage of this method is that it is possible to strictly monitor concentration of each element in order to obtain standard concentrations that well bracket those of fossilized bioapatite preserving almost completely the match between samples and standard matrixes. On the other side, the introduction of several salts significantly complicates the preparation technique, possibly inducing more errors.

After mixture preparation, the powder is homogenized in mortar and pressed in tablets $(500 \mathrm{mg}$ of powder to prepare 12 ton pressed tablets with a $12 \mathrm{~mm}$ diameter).

Following a procedure like that described in Nardelli et al. (2016) we prepared also in-house made standards for trace elements characterization. Proper amounts of a certified solution for trace element determination and micronized ultrapure synthetic hydroxyapatite were mixed and homogenized in an agate mortar and then dried at $60^{\circ} \mathrm{C}$ for $12 \mathrm{~h}$. The resulting powder was then re-homogenized in the agate mortar and pressed at 12 tons into tablets of $12 \mathrm{~mm}$ diameter. Such "standard tablets" at different elements concentration depending on the amount of added certified solution were then checked via LA-ICP-MS using ablation lines to verify whether element distribution was homogeneous (Fig. 1).

\section{Conclusions}

LA-ICPMS analysis is a valuable technique able to provide precise data on the chemical composition (major and trace elements) even of small parts of fossil and recent organisms using bioapatite. These data can so be compared and discussed with cell parameters obtained from $\mu$-XRD. However, once again the strict dependence on the matrix is stressed not only in terms of chemical composition, but also in relative hardness. In fact, as known, one of the main problems of this LA-ICP-MS is to find the proper conditions of ablation which, in turn, depend strictly on the samples and the standards matrix. Matrix matched standards such as the tested NIST BONE ASH and BONE MEAL, as reported are designed for measurement on solution after mineralization; therefore, when employed as solid, cannot provide a proper calibration curve and be used as reference to validate measurements on samples. Therefore, to apply this technique, even if some 
steps were probably done, it is still mandatory to have an adequate feedback system (i.e., another type of chemical determination on solid, such as, for example, $\mathrm{X}$-ray fluorescence).

\section{REFERENCES}

Ferretti A., Malferrari D., Medici L. \& Savioli M. (2017) Diagenesis does not invent anything new: Precise replication of conodont structures by secondary apatite. Scientific Reports, 7(1), article 1624. DOI:10.1038/ s41598-017-01694-4
Hughes J.M. \& Rakovan J. (2002). The Crystal Structure of Apatite, $\mathrm{Ca}_{5}\left(\mathrm{PO}_{4}\right)_{3}(\mathrm{~F}, \mathrm{OH}, \mathrm{Cl})$. In Kohn M.J., Rakovan J. \& Hughes J.M. (eds.), Phosphates: Geochemical, Geobiological and Material Importance. Mineralogical Society of America, Washington DC: 1-12.

Nardelli M. P., Malferrari D., Ferretti A., Bartolini A., Sabbatini A. \& Negri A. (2016). Zinc incorporation in the miliolid foraminifer Pseudotriloculina rotunda under laboratory conditions. Marine Micropaleontology, 126 42-49.
Manuscript received 15 July 2018

Received after revision 2 October 2018

Accepted 3 October 2018 